\title{
The patient experience
}

\author{
Nadia Harbeck · Renate Haidinger
}

Received: 23 January 2007/ Accepted: 17 July 2007

(C) Springer Science+Business Media, LLC 2007

\begin{abstract}
The impact of improved treatments for the management of hormone-sensitive breast cancer extends beyond clinical responses. Thanks to appropriate literature and access to the internet, patient awareness of treatment options has grown and patients are now, in many cases, able to engage their oncologists in informed conversations regarding treatment and what to expect in terms of efficacy and safety. Indeed, patients realize that although there is no cure for metastatic disease, treatment can greatly reduce the risk of progression and in the adjuvant setting, where treatment is administered with a curative intent, current treatment options reduce the risk of relapse. The approval of letrozole throughout the breast cancer continuum has provided patients with many reassuring options. The improvement in outcome with letrozole is achieved without a detrimental effect on overall quality of life. Adverse events such as hot flushes, arthralgia, vaginal dryness, and potential osteoporosis are most significant from the patient's perspective, and it is important that caregivers pay attention to patients experiencing these events, as they can impact compliance unless effectively explained and managed. The major benefits of letrozole are to improve prospects for long-term survivorship in the adjuvant setting and to delay progression and the need for chemotherapy in the metastatic setting.
\end{abstract}

\footnotetext{
N. Harbeck $(\bowtie) \cdot R$. Haidinger

Frauenklinik der Technischen Universität München, Ismaninger Strasse 22, Münich 81675, Germany

e-mail: nadia.harbeck@1rz.tum.de

R. Haidinger

Brustkrebs Deutschland e.V., Charles-de-Gaulle-Str. 6, Münich 81737, Germany

e-mail: renate.haidinger@web.de
}

Keywords Adjuvant therapy - Aromatase inhibitors . Breast cancer $\cdot$ Letrozole $\cdot$ Neoadjuvant therapy $\cdot$ Patient

\section{Introduction}

The diagnosis of breast cancer is a devastating blow for women and is associated with depression, anxiety, and a range of other psychological problems, such as self-blame and negative perception of body-image [1-5]. Newly diagnosed metastatic breast cancer (MBC) is also associated with high levels of psychological morbidity, particularly for younger women [6]. Prevention of relapse is a long-term therapeutic imperative, but the impact of therapy on quality of life (QOL) also needs to be taken into consideration when planning treatment strategies.

All therapeutic modalities for early breast cancer (mastectomy or lumpectomy, radiation, chemotherapy, antibody therapy and endocrine therapy) can have a significant impact on patients' QOL both in the short-term and in the transition period from primary treatment to longterm survivorship [7-9]. Receiving good quality information about prognosis, treatment options, side effects, and risks of breast cancer recurrence is, therefore, important for patients diagnosed with breast cancer [10-13].

The third-generation aromatase inhibitor (AI) letrozole was introduced a decade ago, but at that time, a limited amount of information on breast cancer and its treatment was available to patients. Since then, the international oncology community has made major advances in its knowledge about breast cancer biology, the individualization of treatment options, and communication with patients. Greater understanding of genetics and breast cancer risk has improved approaches for counseling individuals about their susceptibility [14]. In women who 
develop breast cancer, the individualization of treatment is becoming more sophisticated through the use of biomarkers as prognostic and predictive factors. These include human epidermal growth factor receptor (HER) 2 [15, 16], urokinase-type plasminogen activator and plasminogen activator inhibitor type 1 [17, 18], mRNA expression patterns [19, 20], and, more recently, genetic profiling techniques [21, 22]. Individualizing treatment is also made easier by the ability to more accurately determine the patient's risk factors and prognosis; for example, by using the Adjuvant! Online program [23-25]. Recognizing breast cancer overtreatment has also contributed to tailoring treatment according to individual risk [26-30]. Oncology teams have facilitated patient involvement in selecting the most appropriate therapy [24, 31, 32] and have improved the provision of patient information, support, and counseling [33, 34].

At the same time, patients began to organize effectively and expand their access to knowledge of new drugs and treatment paradigms [35-37]. Patients have learned to be informed so that they can have constructive dialogues with their doctors and feel they understand and contribute to treatment decisions [38-42]. Patients who take an active role in the decision-making process perceive that they have a treatment choice, in contrast to those who prefer a shared or passive role [43]. They know they cannot be told at any time during the course of their disease that they are or are not cured; they recognize that breast cancer is a chronic illness. Patients are now empowered with hope and the knowledge that breast cancer can be managed. Moreover, increased survival rates have prompted greater interest in the QOL of breast cancer survivors [44-46].

Better education and improved access to screening has resulted in fewer patients being diagnosed with advanced breast cancer at their first presentation, and consequently, mortality has decreased [29, 47-49]. In addition, more effective adjuvant therapy with third-generation AIs has significantly decreased the risk of recurrence as compared with the previous standard of care based on tamoxifen [5053]. However, there remains a long-term risk of breast cancer recurrence over time [54, 55]. Hormone receptorpositive $(\mathrm{HR}+)$ breast cancer is particularly challenging because of the persistent risk of recurrence with this chronic "smoldering" disease. The Early Breast Cancer Trialists Collaborative Group meta-analysis showed that in untreated women with the same nodal status, the breast cancer death rate is greater for patients with estrogen receptor-negative (ER-) versus ER+ tumors in the first 56 years, but substantially lower for ER- versus ER+ tumors over the next 10 years [56]. Similarly, Saphner reported that beyond 5 years, the risk of recurrence was higher for patients with $\mathrm{HR}+$ tumors than for those with $\mathrm{HR}$ - tumors $(P=0.00002)$ [54].
Patients may experience stress after medical therapy is ended because they feel they have lost a safety net $[57,58]$. This fear is understandable and justifiable in view of the persistent risk of recurrence for $\mathrm{HR}+$ breast cancer. An analysis of the MA.17 trial of extended adjuvant therapy recently showed an increasing risk of disease recurrence over time in patients treated with placebo after discontinuing tamoxifen [59]. Not surprisingly, therefore, patients may be willing to receive long-term therapy (extended adjuvant) to prevent recurrence provided that the benefits outweigh the risks and QOL is maintained [60]. Patients will try to tolerate treatment-related adverse events if there is the prospect of achieving a "cure," i.e. remaining free of relapse during their lifetime.

Tamoxifen was the mainstay of breast cancer therapy, but its time-dependent efficacy and serious adverse events created a need for new therapies [61-63]. The suppression of estrogen was shown to be greater and more selective with third-generation AIs than with first- and second-generation compounds [64], and this has resulted in better clinical outcomes and improved tolerability [65]. This review examines the clinical use of the third-generation AI letrozole from the patient's perspective and assesses how it has improved treatment outcomes across the breast cancer continuum, including advanced or $\mathrm{MBC}$, extended and initial adjuvant therapy, and neoadjuvant therapy.

\section{Metastatic setting}

Endocrine therapy is the first-choice treatment for women with HR+ breast cancer without acute life-threatening symptoms and should be administered for as long as possible before switching to cytotoxic regimens. Endocrine therapy is preferred to cytotoxic chemotherapy because of its more favorable safety profile [66]. Thus, extending the time to the initiation of chemotherapy is important with endocrine therapy, because a considerable proportion of patients who progress to chemotherapy will experience toxic side effects without gaining benefit [67]. The most common acute side effects of chemotherapy, such as leukopenia, alopecia, and nausea and vomiting, are significantly increased in women receiving combination regimens compared with single agents [68]. Chemotherapy can also adversely affect certain aspects of QOL, notably increasing fatigue [69], and some regimens may be associated with severe or life-threatening complications such as cardiac failure [70]. A meta-analysis to review the evidence and determine whether chemotherapy or endocrine therapy has the most beneficial effect on treatment outcomes (survival, response rate, toxicity, and QOL) concluded that in women with $\mathrm{HR}+\mathrm{MBC}$, a policy of treating first with endocrine therapy rather than chemotherapy is 
recommended except in the presence of rapidly progressive disease [71].

Prior to the introduction of third-generation AIs, postmenopausal patients with hormone-responsive MBC had few endocrine therapy options other than tamoxifen [62]. Second-line endocrine agents were limited by safety concerns, including weight gain or the risk of thromboembolism with megestrol acetate [72, 73] and cardiovascular toxicity with aminoglutethimide [65]. Randomized controlled trials demonstrated that letrozole is better tolerated and more effective than these second-line endocrine agents $[65,72,73]$. Furthermore, letrozole has also demonstrated superior early survival compared with tamoxifen as firstline therapy in postmenopausal patients with MBC [74]. Importantly, longer time to disease progression with letrozole versus tamoxifen was achieved without increased time with adverse events and resulted in more qualityadjusted survival for patients on letrozole [75]. Maintaining functional ability is an important goal for patients treated in this setting. A subanalysis by different sites of metastatic lesion and Karnofsky Performance Scores also showed the superiority of letrozole compared with tamoxifen in patients with nonvisceral metastases, with visceral metastases without liver involvement, and with liver metastases [76]. From the patient's perspective, it is important to receive the most effective therapy first-line; therefore, letrozole represents a more attractive option than tamoxifen for postmenopausal women.

Pharmacologic and clinical differences exist between third-generation inhibitors and should be considered in the selection of the most appropriate endocrine therapy [64, 77]. Data from a small randomized crossover trial in 72 postmenopausal women with $\mathrm{HR}+\mathrm{MBC}$ showed that overall QOL was significantly better with letrozole than with anastrozole $(P=0.002$ for mean total Functional Assessment of Cancer Treatment-endocrine symptoms) [78]. Furthermore, letrozole was significantly better tolerated overall than anastrozole. Less nausea, fewer hot flashes, and less abdominal discomfort resulted in almost twice as many patients preferring letrozole to anastrozole [78].

While letrozole is an appropriate first-line therapy for the majority of patients with hormone-responsive MBC, a small subset of patients with HR+ HER2+ tumors have high-risk disease and are candidates for early treatment with chemotherapy plus the anti-HER2 monoclonal antibody trastuzumab [79]. A meta-analysis of 12 studies involving 2,379 patients with MBC demonstrated that HER2+ tumors are less responsive than HER2- tumors to endocrine treatment (overall relative risk 1.42; $95 \%$ confidence interval, 1.32-1.52; $P<0.00001$ ) [80]. Evidence from preclinical models suggests that trastuzumab may overcome relative resistance to endocrine therapy [81], providing the rationale for combining anti-HER2 and endocrine therapies in the clinical setting. Recently, the first published results of an $\mathrm{AI}$ in combination with an antiHER2 antibody (i.e. trastuzumab) show that the combination demonstrated durable responses for at least 1 year in $25 \%$ of patients [82]. Preliminary results from a phase 3 trial (TrAstuzumab in Dual HER2 ER-positive Metastatic breast cancer) demonstrated that the combination of trastuzumab with an AI (anastrozole) was more effective than anastrozole alone in postmenopausal patients with HR+ HER2+ MBC [83]. Another phase 3 trial, which is enrolling more than 1,200 patients in this setting and has just finished recruitment, is investigating letrozole in combination with lapatinib, a dual inhibitor of HER2 and HER1 tyrosine kinases [84]. The strategy of combining letrozole with trastuzumab (as investigated in the evaluation of Letrozole combined with Trastuzumab trial), or another HER2-directed therapy, may allow patients with HR+, HER2+ tumors to safely delay the initiation of cytotoxic chemotherapy.

\section{Adjuvant therapy}

Patients receiving adjuvant therapy expect their treatment to prevent breast cancer recurrence and offer the prospect of cure. However, even modest gains in survival are sufficient to make adjuvant endocrine treatment worthwhile for premenopausal women with early-stage breast cancer [85]. This benefit threshold also appears to apply to women with a higher risk of recurrence for whom adjuvant chemotherapy is indicated [86]. Adjuvant therapy should be tailored to suit the needs of individual patients based on their clinical risk factors, attitudes, and personal life circumstances [25]. However, it is important to recognize that individual preferences cannot always be fully explained on the basis of treatment-related determinants and patient or clinical characteristics [87].

The Anastrozole versus Letrozole: Investigation into Quality of Life study compared the effects of anastrozole and letrozole on estrogen levels, QOL, lipids, and bone health [88]. A total of 185 postmenopausal women with invasive breast cancer were randomized to receive adjuvant therapy with either 12 weeks of letrozole followed by 12 weeks of anastrozole or vice versa. Of the patients who have completed the 12 weeks of treatment $(n=146), 50$ (34\%) had a preference for neither drug, 50 (34\%) preferred anastrozole, and 46 (32\%) preferred letrozole. Both estradiol (E2) and estrone sulfate levels (E1S) were significantly lower on letrozole than on anastrozole $(P<0.000001)$. Thus, $2.5 \mathrm{mg}$ of letrozole reduces circulating E2 and E1S levels to a significantly greater degree than $1 \mathrm{mg}$ of anastrozole, with no significant difference in 
patient preference. The greater suppression of estradiol levels might translate into improved clinical efficacy, although further studies, such as the ongoing Femara Anastrozole Clinical Evaluation trial, are required to confirm these findings.

Patients with HR+ tumors need to consider the prospect of life-long adjuvant therapy in view of the persistent risk of disease recurrence [54, 56, 89]. Following the introduction of third-generation AIs, there is much greater choice in endocrine therapy. The challenge for physicians is to select the most appropriate strategy to suit individual patient circumstances. Letrozole first entered the adjuvant setting as a treatment option for patients completing 5 years of tamoxifen [90] and has demonstrated clinical superiority over tamoxifen as initial adjuvant therapy [51] and neoadjuvant therapy [91].

\section{Neoadjuvant therapy}

Neoadjuvant endocrine therapy with letrozole is an attractive option for some postmenopausal patients with HR+ early breast cancer [92], including elderly patients who are unable or unwilling to undergo chemotherapy or surgery, and patients with locally advanced HR+ tumors who wish to have breast-conserving surgery but are not suited for preoperative chemotherapy [91, 93]. In a randomized controlled trial, letrozole demonstrated a superior overall objective response rate and rate of breast-conserving surgery compared with tamoxifen as neoadjuvant therapy [91]. Currently, letrozole is the only AI approved in the neoadjuvant setting (in the United Kingdom and 16 other countries worldwide). It provides a reasonable therapeutic alternative to preoperative chemotherapy in postmenopausal women with $\mathrm{HR}+$ disease in clinical situations where the low toxicity of the regimen is considered an advantage, e.g. in women older than 70 years [91]. However, patients need to be aware that a longer course of therapy may be required to achieve an objective response than is the case with neoadjuvant chemotherapy [94]. In one study, neoadjuvant letrozole was safely given over 12 months to postmenopausal women with large operable or locally advanced HR+ breast cancers [94]. A longer treatment course may suit some patients and give them more time to consider their options for surgery, radiotherapy, and chemotherapy.

Neoadjuvant therapy with letrozole could be considered a sensitivity test of endocrine therapy that might be incorporated into strategies to individualize adjuvant treatment according to response [95]. This would provide reassurance to patients that they will be receiving an adjuvant endocrine therapy that has shown activity against their tumor. Objective assessment of the antitumor activity of neoadjuvant letrozole can be made on the basis of response rate and by analysis of predictive biomarkers. In one study, neoadjuvant letrozole was found to inhibit tumor proliferation (determined by the biomarker Ki67) more effectively than tamoxifen [95]. Letrozole was effective independently of HER2 expression status, although the greatest difference between letrozole and tamoxifen was seen in tumors that were HR+ and HER $1 / 2+$. Recent evidence has suggested that HER2+ tumors can continue to proliferate despite neoadjuvant letrozole or tamoxifen treatment, which could imply therapeutic resistance that may manifest later in the clinical course of the disease [96].

Biomarker studies may also reveal differences between AIs. In a randomized comparative trial, letrozole and anastrozole significantly reduced proliferation in $\mathrm{HR}+$, HER2+ or HER2- tumors [97]. Decreased proliferation was seen at all Allred ER expression levels with both agents, but only letrozole showed a significant effect in the lower ER cases. In addition, more cases showed a reduction in progesterone receptor $(\mathrm{PgR})$ expression following letrozole than anastrozole [97]. Another study showed evidence of a decrease in HER2 expression after neoadjuvant treatment with letrozole [98].

Although complex, biomarkers may become increasingly important from a patient's perspective, because they can help to improve the individualization of treatment. Furthermore, biomarkers may be useful to predict the risk of resistance to endocrine therapy and the need to consider alternative approaches in the future, such as combination therapies or cytotoxic chemotherapy. Knowing what to expect next is important for patients. However, further work is necessary to validate the use of clinical markers and biomarkers in the neoadjuvant setting as surrogate end points for long-term outcomes [96].

\section{Early adjuvant therapy}

Tamoxifen was the gold standard endocrine therapy for all women with $\mathrm{HR}+$ breast cancer until recent results from large randomized trials challenged this paradigm for postmenopausal women [50, 51, 99]. Oncologists and patients now face an important choice when selecting adjuvant endocrine treatment $[66,100]$, whether to start with the most potent endocrine therapy (an AI) upfront or to start with tamoxifen and switch to an AI inhibitor after 2-5 years. The ongoing Breast International Group (BIG) 1-98 randomized trial is expected to provide more information on the benefits of switching to letrozole after 2-3 years on tamoxifen and will clarify which is the optimal strategy. The final results are expected to be released in 2008 [51], but until then, the most appropriate endocrine therapy will need to be selected on the basis of currently available evidence. The MA.17 trial has already 
demonstrated that letrozole treatment is beneficial after 5 years of adjuvant tamoxifen [90, 101, 102].

Patients will ideally wish to receive treatment that provides the greatest long-term efficacy with the lowest risk of adverse events. BIG 1-98 showed that letrozole was significantly more effective than tamoxifen as initial adjuvant endocrine therapy [51]. Moreover, tamoxifen is perceived to be more toxic than AIs, largely because of well-publicized "scares" about increased risk of uterine cancer and thrombosis [61, 103]. These side effects and vaginal bleeding were reported for tamoxifen in BIG 1-98, whereas letrozole was associated with more skeletal events. The overall rate of cardiovascular events was not significantly different between the groups. Letrozole was also shown to be extremely well-tolerated in comparison with placebo in the MA.17 trial $[90,101]$. With the exception of adverse events related to suppression of estrogen, there was no difference in adverse events (Table 1).

Based on the results from the BIG 1-98 and the Anastrozole and Tamoxifen Alone or in Combination (ATAC) trial, which compared upfront AIs with tamoxifen, it is clear that all postmenopausal women with $\mathrm{HR}+$ breast cancer should be given the opportunity to receive adjuvant use of an AI, and this recommendation is now reflected in internationally recognized treatment guidelines $[66,100$, 104, 105]. Patients with HR+ breast cancer considered eligible for adjuvant chemotherapy because of their increased risk for relapse should also be candidates for the most effective adjuvant endocrine strategy [100]. Of note, the BIG 1-98 trial showed that adjuvant letrozole provides significant disease-free survival (DFS) benefits for patients at increased risk of recurrence, specifically patients with node-positive tumors, large primary tumors $(>2 \mathrm{~cm})$, and recipients of chemotherapy and also demonstrated a significant reduction in the risk of distant recurrence, a well-known predictor of breast cancer death [51]. Additional analyses of data from BIG 1-98 to determine the predictive value of centrally tested ER, PgR, and HER2 status on the response to letrozole and tamoxifen indicate that there is no difference in subgroups by ER/PR or HER2 status regarding the superiority of upfront letrozole versus tamoxifen [106]. Low-risk patients with HR+ breast cancer who do not receive adjuvant chemotherapy are also candidates for AIs [104] because of the persistent risk of relapse [54, 56].

While it is known that tamoxifen loses effectiveness after 5 years [62, 63], the optimal duration of initial therapy with an AI remains to be determined [107]. The MA.17 randomized controlled trial of extended adjuvant endocrine therapy has already shown that letrozole treatment is beneficial after 5 years of tamoxifen in postmenopausal patients $[90,101]$, but there are no equivalent data on the use of tamoxifen after initial AI therapy in the adjuvant setting [100]. Furthermore, the efficacy of switching to another AI in patients who discontinue treatment with letrozole is not known. Therefore, patients starting upfront therapy with letrozole will need reassurance that according to present knowledge, treatment can be continued for up to 5 years, and other options will be available down the line. In addition, patients will require information about the potential long-term impact of AIs on bone and the cardiovascular system [107].

According to the current treatment guidelines [66, 100, 104, 105], patients already taking a course of adjuvant tamoxifen may wish to switch to anastrozole or exemestane, as these AIs have demonstrated efficacy in this setting [52, 108, 109]. Although recent data have shown that this sequential adjuvant strategy is associated with a survival advantage $[53,110,111]$, it is important to note that these data were obtained from a selected population comprising patients at randomization who were diseasefree after 2-3 years of tamoxifen. It is therefore not valid to make a direct comparison with an unselected population treated in trials of upfront AI therapy. The decision to switch endocrine therapy after 2-3 years, i.e. for a sequential tamoxifen-AI strategy, should be based on an individual's risk for recurrence, risk for osteoporosis, and ability to tolerate tamoxifen. Importantly, BIG 1-98 is expected to provide more information on the benefits of switching to letrozole after 2-3 years of tamoxifen, and will clarify whether upfront or sequential AI use is the optimal strategy. The final results will be released in 2008 [51].

\section{Extended adjuvant (including late extended adjuvant) therapy}

Many patients fear breast cancer recurrence [112] and are reassured by the "safety net" of continuing medical treatment and monitoring [9]. The MA.17 trial showed that extended adjuvant therapy with letrozole gives patients the opportunity of retaining the safety net for at least 5 more years after adjuvant tamoxifen [101], and these results led to its approval in this indication. Currently, letrozole is the only AI approved as an extended adjuvant therapy.

The final analysis of MA.17 after a median follow-up of 30 months showed letrozole significantly improved DFS (42\% reduction in risk vs. placebo), distant DFS (40\% reduction in risk vs. placebo) and, in node-positive patients, overall survival (39\% reduction in risk vs. placebo) [101]. A recent cohort analysis of the MA.17 trial data suggested that the longer patients are exposed to letrozole, the greater the benefit, at least out to 48 months [59]. In addition, an extension to the MA.17 trial (MA.17 Re-randomization) is 
Table 1 Safety profile of letrozole in comparison with placebo (A) and tamoxifen (B) reported in postmenopausal women with early breast cancer

\begin{tabular}{|c|c|c|}
\hline \multicolumn{3}{|l|}{ Placebo } \\
\hline \multirow[t]{2}{*}{ Acute toxicities reported } & \multicolumn{2}{|c|}{ Total number (\%), any grade ${ }^{101}$} \\
\hline & Letrozole $(n=2,572)$ & Placebo $(n=2,577)$ \\
\hline Edema & $571(22)$ & $542(21)$ \\
\hline Hypertension & $130(5)$ & $129(5)$ \\
\hline Hot flushes & $1,486(58)^{\mathrm{a}}$ & $1383(54)$ \\
\hline Fatigue & $999(39)$ & $998(39)$ \\
\hline Sweating & $782(30)$ & $760(29)$ \\
\hline Anorexia & $142(6)^{\mathrm{a}}$ & $110(4)$ \\
\hline Constipation & $363(14)$ & $382(15)$ \\
\hline Diarrhea & $168(7)$ & $176(7)$ \\
\hline Nausea & $308(12)$ & $314(12)$ \\
\hline Vaginal bleeding & $145(6)$ & $196(8)^{\mathrm{a}}$ \\
\hline Infection without neutropenia & $124(5)$ & $112(4)$ \\
\hline Arthritis & $167(6)$ & $137(5)$ \\
\hline Hypercholesterolemia & $418(16)$ & $411(16)$ \\
\hline Dizziness & $458(18)$ & $441(17)$ \\
\hline Insomnia & $166(6)$ & $135(5)$ \\
\hline Depression & $143(6)$ & $131(5)$ \\
\hline Headache & $706(27)$ & $685(27)$ \\
\hline Arthralgia & $651(25)^{\mathrm{a}}$ & $532(21)$ \\
\hline Myalgia & $380(15)^{\mathrm{a}}$ & $310(12)$ \\
\hline Bone pain & $141(5)$ & $149(6)$ \\
\hline Dyspnea & $161(6)$ & $163(6)$ \\
\hline Alopecia & $126(5)^{\mathrm{a}}$ & $89(3)$ \\
\hline Vaginal dryness & $147(6)$ & $129(5)$ \\
\hline
\end{tabular}

Tamoxifen

\begin{tabular}{lll}
\hline Worst grade adverse events recorded within first 28 days & \multicolumn{2}{l}{ Total number $(\%)$, any grade } \\
\cline { 2 - 3 } & Letrozole $(n=3,975)$ & Tamoxifen $(n=3,988)$ \\
\hline CVA or TIA & $39(1.0)$ & $41(1.0)$ \\
Thromboembolic event & $61(1.5)$ & $140(3.5)^{\mathrm{a}}$ \\
Cardiac event (IHD, CF) & $162(4.1)$ & $153(3.8)$ \\
Other CV event & $19(0.5)^{\mathrm{a}}$ & $8(0.2)$ \\
Vaginal bleeding & $132(3.3)$ & $263(6.6)$ \\
Hot flushes & $1332(33.5)$ & $1516(38.0)^{\mathrm{a}}$ \\
Night sweats & $554(13.9)$ & $647(16.2)^{\mathrm{a}}$ \\
Fracture & $225(5.7)^{\mathrm{a}}$ & $159(4.0)$ \\
Arthralgia & $806(20.3)^{\mathrm{a}}$ & $491(12.3)$ \\
Myalgia & $254(6.4)$ & $243(6.1)$
\end{tabular}

$C V$ cardiovascular, $C V A$ cerebrovascular accident, $T I A$ transient ischemic attack, $I H D$ ischemic heart disease, $C F$ cardiac failure

a Significant difference

being conducted to determine the benefits of continuing letrozole for a further 5 years [102].

When a planned interim analysis of MA.17 revealed a significant advantage for letrozole, the trial was unblinded and patients on placebo were given the option to switch to letrozole [90]. In this non-randomized comparison, women from the placebo arm who elected to switch to letrozole also experienced an improvement in outcome when compared with those who elected to have no treatment [102]. 
Recurrence risk persists beyond the completion of adjuvant therapy, even in patients at low risk of recurrence. One study shows that with systemic adjuvant therapy, patients with node-negative breast cancer have a $\geq 25 \%$ 10 -year risk of relapse and a corresponding 10-year breast cancer death rate as high as $\geq 10 \%$, depending on tumor grade and size [113]. Thus, the proven efficacy of letrozole given after a tamoxifen-free period means that physicians need to discuss the option of restarting endocrine therapy with almost all patients. Physicians have to consider how best to address this topic with patients who are up to 2-3 years out beyond their initial 5 years of tamoxifen, i.e. about 5-8 years after their initial diagnosis. This will be a major communication challenge and create a dilemma for patients who may feel well and have put their breast cancer behind them.

\section{Safety and compliance issues}

The clinical benefits of AIs and tamoxifen are generally achieved without a major detrimental effect on overall QOL [114]. Data from the MA.17 trial, which is the only large adjuvant trial comparing AI therapy not with tamoxifen but with placebo, showed that overall QOL was maintained during extended therapy with letrozole, and only a minority of patients experienced substantial changes in QOL, which were compatible with a reduction in estrogen synthesis [115]. It is important to recognize that patients may attribute such changes to their treatment, whereas they could in fact be symptoms of menopause [116]. However, side effects do occur, which not only affect patient adherence to endocrine therapy [117] but can also lead to additional morbidity and even serious or lifethreatening complications in a small minority of patients [51, 52, 90, 99, 108, 109].

The main safety concerns with long-term estrogen deprivation include potential effects on bone health, cardiac health, lipid profile, cognitive functioning, and sexual health [100]. The MA.17 trial showed that letrozole is welltolerated in comparison with placebo [101], and BIG 1-98 showed that letrozole was better tolerated than tamoxifen [51] (Table 1). A recent patient-reported outcomes study in 104 tamoxifen-intolerant women found that switching to letrozole was associated with a significant reduction in hot flushes $(P=0.001)$ and significant improvements in QOL $(P=0.001)$ and mood $(P=0.04)$. Furthermore, when given the choice of continuing therapy, $66 \%$ of women indicated that they preferred to remain on letrozole, while only $24 \%$ preferred to go back to tamoxifen [118].

Despite an increase in newly diagnosed osteoporosis with AIs, no significant difference in clinical fracture rate was seen between letrozole and placebo [101]. A companion study to MA.17 showed that there was only a modest increase in bone resorption and reduction in bone mineral density (BMD) in the spine and hip with letrozole compared with placebo [119]. Consequently, patients should be made aware of the risk of osteoporosis and given advice on lifestyle measures (e.g. exercise, diet, vitamins) to reduce risk. A baseline BMD measurement should be obtained for all patients before starting therapy with an AI. BMD should then be measured annually, and patients at high risk of osteoporosis should be considered for prophylactic use of a bisphosphonate [120, 121]. However, recent data from ATAC may be reassuring for patients facing upfront AI therapy, since they indicate that women with normal initial BMD did not develop osteoporosis during a 5-year AI treatment [122].

Letrozole has been associated with an increase in arthralgia compared with placebo or tamoxifen, and myalgia compared with placebo [51, 101]. Arthralgia and joint pain can be bothersome and may lead to impaired mobility. Patients need to be advised that constant exercising of the joints will alleviate this adverse event and that use of nonsteroidal anti-inflammatory drugs over a certain period of time may be helpful. Moreover, these complaints seem to be most frequent in the beginning of AI therapy [123].

Another potential consequence of endocrine therapy is a detrimental effect on sexual health [115, 116]. Vaginal dryness is a consequence of menopause and treatments that cause menopausal symptoms, and has an important bearing on sexual health and well-being of breast cancer survivors [124]. Vaginal dryness can be a significant problem that can interfere with the stability of relationships [125], and patients need to receive counseling with regard to this issue [126]. It has been shown that clinical assessment and an active intervention program for menopausal symptom management in breast cancer survivors can lead to an improvement in sexual functioning [127]. A recent report demonstrated that the use of local estradiol therapy may cause elevation of serum estradiol and may therefore be contraindicated in postmenopausal women on AI therapy [128]. So far, such data do not exist for estradiol-containing compounds; thus, local estradiol treatment may be indicated in individual cases. Androgen treatment may also improve sexual well-being in postmenopausal women [129], yet the oncological safety of this approach has not been validated in patients receiving AI therapy. Of note, the incidence of vaginal dryness in the MA.17 trial was similar in the letrozole and placebo groups (Table 1) [101].

Differential effects on lipid profiles and cardiac risk have been reported between tamoxifen and AIs [51, 130, 131], but data from the Letrozole, Exemestane, and Anastrozole Pharmacodynamics trial, directly comparing the effects of anastrozole, letrozole, and exemestane on 
lipid profiles in healthy postmenopausal women, suggest that the steroidal and nonsteroidal inhibitors have a similar impact on lipid profiles [132]. On the basis of evidence from large randomized trials, when comparing letrozole with tamoxifen or placebo, it appears that letrozole does not have clinically relevant adverse effects on lipids or cardiac risk during long-term adjuvant therapy, although further assessment is warranted [51, 101, 133].

While letrozole is well-tolerated, and any side effects that do occur can be managed, it is essential that patients are motivated to stay on therapy. This can be a particular challenge in the extended adjuvant setting. Thus, as patients now face the prospect of receiving endocrine therapy for 10 years or more, it is important to consider the overall life-long benefits and risks from the individual's perspective. A low burden of adverse events and maintenance of QOL is important in maintaining adherence to long-term treatment [60]. In the MA.17 trial, the rate of patients choosing to discontinue therapy during the first year was similar for letrozole $(n=256 / 2,575)$ and placebo $(n=254 / 2,582)$ [90]. Letrozole is ingested orally and can be safely and conveniently taken at home. Physician contact with oral endocrine therapy can be much less frequent than, for example, with orally active chemotherapy where regular blood tests, side-effect monitoring, and resulting dose modifications make frequent physician contact mandatory. Patients with breast cancer prefer oral cancer therapy providing that it does not compromise treatment efficacy [134].

\section{Conclusions}

Patients with breast cancer face bewildering choices at a time when they are experiencing highly stressful circumstances. Moreover, many of these women are not well-informed and thus are not able to take part in treatment decisions. The Gathering Information on Adjuvant Endocrine therapy initiative decided to delineate women's knowledge and experience of adjuvant endocrine therapy. Results thus far indicate that only $22 \%$ of patients were fully or highly involved in the decision to start adjuvant endocrine therapy $[135,136]$. Many of the women who took part in the survey were not satisfied with the degree to which they were involved in treatment decision-making, and women 60 years or older had the lowest levels of involvement [135, 136]. The results from this survey show that information provided to patients about adjuvant endocrine therapy is suboptimal and indicate the need for programs to raise patient awareness. The medical community has a responsibility to help patients understand their prospects for survival and make the right choices about treatment [24]. Doctor-patient discussions and programs to raise patient awareness will increase patients' knowledge about the individualization of treatment and may increase the number of women who take an active role in treatment decisions.

Patients with hormone-responsive breast cancer should be offered the opportunity of receiving the most effective endocrine therapy. Clinical evidence suggests that postmenopausal women should receive an AI rather than tamoxifen as their first option if tumor characteristics and individual side-effect profiles support this choice. Letrozole has consistently demonstrated superiority over tamoxifen in the metastatic and adjuvant treatment settings [51, 74, 91, 101]. As a result of its innovative clinical trial program [51, $74,101]$, letrozole is approved for use in postmenopausal women throughout the breast cancer care continuum [137]. From the patient's perspective, the major benefits of letrozole are improving prospects for long-term survivorship ("cure") in the adjuvant setting and delaying progression and the need for chemotherapy in the metastatic setting.

Endocrine therapy is very effective, has a generally favorable safety profile, and adds to the efficacy of chemotherapy. However, a major challenge for both physicians and patients is ensuring compliance with longterm daily therapy. This may be a particular problem in the extended adjuvant setting, where the patient may face the prospect of life-long therapy. As patients no longer feel sick, it is understandable that they may forget to take a dose and gradually lose interest in continuing with the treatment. Letrozole is well-tolerated and, as with all AIs, the majority of adverse events are secondary to the suppression of estrogen. The most important adverse events from the patient's perspective are the "visible" ones, such as hot flushes, vaginal dryness, and arthralgias. To achieve optimal compliance, patients need to feel that physicians are taking their adverse events seriously and taking appropriate steps to alleviate any problems. Physicians who treat very few breast cancer patients may not have sufficient experience with AIs to satisfactorily manage individuals who are experiencing these adverse events.

Letrozole is likely to continue to play a major role in the management of breast cancer in all settings (see the paper in this supplement by Drs. Ellis and Ma, on Femara ${ }^{\mathbb{R}}$ and the future). Considering its efficacy and favorable sideeffect profile, it is the logical choice for inclusion in new regimens, including combinations with novel agents. As the future unfolds, the management of breast cancer is set for further change, and it is essential that patients are informed and educated so that they can actively participate in treatment decisions and thus derive the most benefit from treatment advances. 


\section{References}

1. Lehto US, Ojanen M, Kellokumpu-Lehtinen P (2005) Predictors of quality of life in newly diagnosed melanoma and breast cancer patients. Ann Oncol 16:805-816

2. Burgess C, Cornelius V, Love S, Graham J, Richards M, Ramirez A (2005) Depression and anxiety in women with early breast cancer: five year observational cohort study. BMJ 330:702

3. Bennett KK, Compas BE, Beckjord E, Glinder JG (2005) Selfblame and distress among women with newly diagnosed breast cancer. J Behav Med 28:313-323

4. Nosarti C, Roberts JV, Crayford T, McKenzie K, David AS (2002) Early psychological adjustment in breast cancer patients: a prospective study. J Psychosom Res 53:1123-1130

5. Koopman C, Angell K, Turner-Cobb JM, Kreshka MA, Donnelly P, McCoy R, Turkseven A, Graddy K, Giese-Davis J, Spiegel D (2001) Distress, coping, and social support among rural women recently diagnosed with primary breast cancer. Breast J 7:25-33

6. Turner J, Kelly B, Swanson C, Allison R, Wetzig N (2005) Psychosocial impact of newly diagnosed advanced breast cancer. Psychooncology 14:396-407

7. Avis NE, Crawford S, Manuel J (2005) Quality of life among younger women with breast cancer. J Clin Oncol 23: 3322-3330

8. Ganz PA, Guadagnoli E, Landrum MB, Lash TL, Rakowski W, Silliman RA (2003) Breast cancer in older women: quality of life and psychosocial adjustment in the 15 months after diagnosis. J Clin Oncol 21:4027-4033

9. Ganz PA, Kwan L, Stanton AL, Krupnick JL, Rowland JH, Meyerowitz BE, Bower JE, Belin TR (2004) Quality of life at the end of primary treatment of breast cancer: first results from the moving beyond cancer randomized trial. J Natl Cancer Inst 96:376-387

10. Vivar CG, McQueen A (2005) Informational and emotional needs of long-term survivors of breast cancer. J Adv Nurs 51:520-528

11. Lobb EA, Kenny DT, Butow PN, Tattersall MH (2001) Women's preferences for discussion of prognosis in early breast cancer. Health Expect 4:48-57

12. Geiger AM, Mullen ES, Sloman PA, Edgerton BW, Petitti DB (2000) Evaluation of a breast cancer patient information and support program. Eff Clin Pract 3:157-165

13. Keller JS (2006) Implementation of a prechemotherapy educational intervention for women newly diagnosed with breast cancer. Clin J Oncol Nurs 10:57-60

14. Green MJ, McInerney AM, Biesecker BB, Fost N (2001) Education about genetic testing for breast cancer susceptibility: patient preferences for a computer program or genetic counselor. Am J Med Genet 103:24-31

15. Nicolini A, Carpi A, Tarro G (2006) Biomolecular markers of breast cancer. Front Biosci 11:1818-1843

16. van de Vijver M (2005) Gene-expression profiling and the future of adjuvant therapy. Oncologist 10 (Suppl 2):30-34

17. Jänicke F, Prechtl A, Thomssen C, Harbeck N, Meisner C, Untch M, Sweep CG, Selbmann HK, Graeff H, Schmitt M; German N0 Study Group (2001) Randomized adjuvant chemotherapy trial in high-risk, lymph node-negative breast cancer patients identified by urokinase-type plasminogen activator and plasminogen activator inhibitor type 1. J Natl Cancer Inst 93:913-920

18. Harbeck N, Kates RE, Look MP, Meijer-Van Gelder ME, Klijn JG, Kruger A, Kiechle M, Janicke F, Schmitt M, Foekens JA (2002) Enhanced benefit from adjuvant chemotherapy in breast cancer patients classified high-risk according to urokinase-type plasminogen activator (uPA) and plasminogen activator inhibitor type $1(n=3424)$. Cancer Res 62: 4617-4622

19. van 't Veer LJ, Dai H, van de Vijver MJ, He YD, Hart AA, Mao M, Peterse HL, van der Kooy K, Marton MJ, Witteveen AT, Schreiber GJ, Kerkhoven RM, Roberts C, Linsley PS, Bernards R, Friend SH (2002) Gene expression profiling predicts clinical outcome of breast cancer. Nature 415:530-536

20. Paik S, Shak S, Tang G, Kim C, Baker J, Cronin M, Baehner FL, Walker MG, Watson D, Park T, Hiller W, Fisher ER, Wickerham DL, Bryant J, Wolmark N (2004) A Multigene Assay to predict recurrence of tamoxifen-treated, node-negative breast cancer. N Engl J Med 351:2817-2826

21. Sotiriou C, Wirapati P, Loi S, Harris A, Fox S, Smeds J, Nordgren H, Farmer P, Praz V, Haibe-Kains B, Desmedt C, Larsimont D, Cardoso F, Peterse H, Nuyten D, Buyse M, Van de Vijver MJ, Bergh J, Piccart M, Delorenzi M (2006) Gene expression profiling in breast cancer: understanding the molecular basis of histologic grade to improve prognosis. J Natl Cancer Inst 98:262-272

22. Pittman J, Huang E, Dressman H, Horng CF, Cheng SH, Tsou MH, Chen CM, Bild A, Iversen ES, Huang AT, Nevins JR, West $M$ (2004) Integrated modeling of clinical and gene expression information for personalized prediction of disease outcomes. Proc Natl Acad Sci USA 101:8431-8436

23. Adjuvant! Online. Decision making tools for health care professionals. http://www.adjuvantonline.com Cited 17 January 2007

24. Ravdin PM, Siminoff LA, Davis GJ, Mercer MB, Hewlett J, Gerson N, Parker HL (2001) Computer program to assist in making decisions about adjuvant therapy for women with early breast cancer. J Clin Oncol 19:980-991

25. Siminoff LA, Gordon NH, Silverman P, Budd T, Ravdin PM (2006) A decision aid to assist in adjuvant therapy choices for breast cancer. Psychooncology 15:1001-1013

26. Warren R, Eleti A (2006) Overdiagnosis and overtreatment of breast cancer: is overdiagnosis an issue for radiologists? Breast Cancer Res 8:205

27. Jones JL (2006) Overdiagnosis and overtreatment of breast cancer: progression of ductal carcinoma in situ: the pathological perspective. Breast Cancer Res 8:204

28. Kumar AS, Bhatia V, Henderson IC (2005) Overdiagnosis and overtreatment of breast cancer: rates of ductal carcinoma in situ: a US perspective. Breast Cancer Res 7:271-275

29. Moss S (2005) Overdiagnosis and overtreatment of breast cancer: overdiagnosis in randomised controlled trials of breast cancer screening. Breast Cancer Res 7:230-234

30. Duffy SW, Agbaje O, Tabar L, Vitak B, Bjurstam N, Bjorneld L, Myles JP, Warwick J (2005) Overdiagnosis and overtreatment of breast cancer: estimates of overdiagnosis from two trials of mammographic screening for breast cancer. Breast Cancer Res 7:258-265

31. Whelan T, Sawka C, Levine M, Gafni A, Reyno L, Willan A, Julian J, Dent S, Abu-Zahra H, Chouinard E, Tozer R, Pritchard $\mathrm{K}$, Bodendorfer I (2003) Helping patients make informed choices: a randomized trial of a decision aid for adjuvant chemotherapy in lymph node-negative breast cancer. J Natl Cancer Inst 95:581-587

32. Whelan T, Levine M, Willan A, Gafni A, Sanders K, Mirsky D, Chambers S, O'Brien MA, Reid S, Dubois S (2004) Effect of a decision aid on knowledge and treatment decision making for breast cancer surgery: a randomized trial. JAMA 28;292: 435-441

33. Liang W, Burnett CB, Rowland JH, Meropol NJ, Eggert L, Hwang YT, Silliman RA, Weeks JC, Mandelblatt JS (2002) Communication between physicians and older women with 
localized breast cancer: implications for treatment and patient satisfaction. J Clin Oncol 20:1008-1016

34. Gray RE, Goel V, Fitch MI, Franssen E, Labrecque M (2002) Supportive care provided by physicians and nurses to women with breast cancer. Results from a population-based survey. Support Care Cancer 10:647-652

35. Esquivel A, Meric-Bernstam F, Bernstam EV (2006) Accuracy and self correction of information received from an internet breast cancer list: content analysis. BMJ 22;332:939-942

36. Rozmovits L, Ziebland S (2004) What do patients with prostate or breast cancer want from an Internet site? A qualitative study of information needs. Patient Educ Couns 53:57-64

37. Winzelberg AJ, Classen C, Alpers GW, Roberts H, Koopman C, Adams RE, Ernst H, Dev P, Taylor CB (2003) Evaluation of an internet support group for women with primary breast cancer. Cancer 97:1164-1173

38. Rankin N, Newell S, Sanson-Fisher R, Girgis A (2000) Consumer participation in the development of psychosocial clinical practice guidelines: opinions of women with breast cancer. Eur J Cancer Care (Engl) 9:97-104

39. Mallinger JB, Griggs JJ, Shields CG (2005) Patient-centered care and breast cancer survivors' satisfaction with information. Patient Educ Couns 57:342-349

40. Lantz PM, Janz NK, Fagerlin A, Schwartz K, Liu L, Lakhani I, Salem B, Katz SJ (2005) Satisfaction with surgery outcomes and the decision process in a population-based sample of women with breast cancer. Health Serv Res 40:745-767

41. Sabo B, St-Jacques N, Rayson D (2007) The decision-making experience among women diagnosed with stage I and II breast cancer. Breast Cancer Res Treat 102:51-59

42. Oskay-Oezcelik G, Lehmacher W, Mirz R, Christ H, Kaufmann M, Bamberg M, Werner L, Wallwiener D, Overkamp F, Hindenburg HJ, Sehouli J (2006) What do adjuvant and metastatic breast cancer patients (BC) expect from their doctors? Final results of a German survey in 617 patients. J Clin Oncol 24(18S):321s. Abstract 6085

43. Jansen SJ, Otten W, Stiggelbout AM (2006) Factors affecting patients' perceptions of choice regarding adjuvant chemotherapy for breast cancer. Breast Cancer Res Treat 99:35-45

44. Ashing-Giwa KT, Padilla G, Tejero J, Kraemer J, Wright K, Coscarelli A, Clayton S, Williams I, Hills D (2004) Understanding the breast cancer experience of women: a qualitative study of African American, Asian American, Latina and Caucasian cancer survivors. Psychooncology 13:408-428

45. McCarthy NJ (2004) Care of the breast cancer survivor: increased survival rates present a new set of challenges. Postgrad Med 116:39-40, 42, 45-46

46. Mrozek E, Shapiro CL (2005) Survivorship and complications of treatment in breast cancer. Clin Adv Hematol Oncol 3: 211-238

47. Fracheboud J, Otto SJ, van Dijck JA, Broeders MJ, Verbeek AL, de Koning HJ; National Evaluation Team for Breast cancer screening (NETB) (2004) Decreased rates of advanced breast cancer due to mammography screening in The Netherlands. Br J Cancer 91:861-867

48. Moss S, Waller M, Anderson TJ, Cuckle H; Trial Management Group (2005) Randomised controlled trial of mammographic screening in women from age 40: predicted mortality based on surrogate outcome measures. Br J Cancer 92:955-960

49. Elmore JG, Armstrong K, Lehman CD, Fletcher SW (2005) Screening for breast cancer. JAMA 293:1245-1256

50. Howell A, Cuzick J, Baum M, Buzdar A, Dowsett M, Forbes JF, Hoctin-Boes G, Houghton J, Locker GY, Tobias JS; ATAC Trialists' Group (2005) Results of the ATAC (Arimidex, Tamoxifen, Alone or in Combination) trial after completion of 5 years' adjuvant treatment for breast cancer. Lancet 365:60-62
51. Thurlimann B, Keshaviah A, Coates AS, Mouridsen H, Mauriac L, Forbes JF, Paridaens R, Castiglione-Gertsch M, Gelber RD, Rabaglio M, Smith I, Wardley A, Price KN, Goldhirsch A; for the Breast International Group (BIG) 1-98 Collaborative Group (2005) A comparison of letrozole and tamoxifen in postmenopausal women with early breast cancer. N Engl J Med 353:2747-2757

52. Coombes RC, Hall E, Gibson LJ, Paridaens R, Jassem J, Delozier T, Jones SE, Alvarez I, Bertelli G, Ortmann O, Coates AS, Bajetta E, Dodwell D, Coleman RE, Fallowfield LJ, Mickiewicz E, Andersen J, Lonning PE, Cocconi G, Stewart A, Stuart N, Snowdon CF, Carpentieri M, Massimini G, Bliss JM; Intergroup Exemestane Study (2004) A randomized trial of exemestane after two to three years of tamoxifen therapy in postmenopausal women with primary breast cancer. $\mathrm{N}$ Engl $\mathrm{J}$ Med 350:1081-1092. Erratum in: N Engl J Med 2004; 351:2461

53. Coombes RC, Paridaens R, Jassem J, Van de Velde CJ, Delozier T, Jones SE, Hall E, Kilburn LS, Snowdon CF, Bliss JM, for the Intergroup Exemestane Study (IES) (2006) First mature analysis of the Intergroup Exemestane Study. J Clin Oncol 24(18S):933s. Abstract LBA527

54. Saphner T, Tormey DC, Gray R (1996) Annual hazard rates of recurrence for breast cancer after primary therapy. J Clin Oncol 14:2738-2746

55. Anderson WF, Jatoi I, Devesa SS (2005) Distinct breast cancer incidence and prognostic patterns in the NCI's SEER program: suggesting a possible link between etiology and outcome. Breast Cancer Res Treat 90:127-137

56. Early Breast Cancer Trialists' Collaborative Group (EBCTCG) (2005) Effects of chemotherapy and hormonal therapy for early breast cancer on recurrence and 15-year survival: an overview of the randomised trials. Lancet 365:1687-1717

57. Ward SE, Viergutz G, Tormey D, deMuth J, Paulen A (1992) Patients' reactions to completion of adjuvant breast cancer therapy. Nurs Res 41:362-366

58. Green BL, Rowland JH, Krupnick JL, Epstein SA, Stockton P, Stern NM, Spertus IL, Steakley C (1998) Prevalence of posttraumatic stress disorder in women with breast cancer. Psychosomatics 39:102-111

59. Ingle JN, Tu D, Pater JL, Martino S, Robert NJ, Muss HB, Piccart MJ, Castiglione M, Shepherd LE, Pritchard KI, Livingston RB, Davidson NE, Norton L, Perez EA, Abrams JS, Cameron DA, Palmer MJ, Goss PE (2006) Duration of letrozole treatment and outcomes in the placebo-controlled NCIC CTG MA.17 extended adjuvant therapy trial. Breast Cancer Res Treat 99:295-300

60. Fallowfield L (2005) Acceptance of adjuvant therapy and quality of life issues. Breast 14:612-616

61. Fisher B, Costantino JP, Redmond CK, Fisher ER, Wickerham DL, Cronin WM (1994) Endometrial cancer in tamoxifentreated breast cancer patients: findings from the National Surgical Adjuvant Breast and Bowel Project (NSABP) B-14. J Natl Cancer Inst 86:527-537

62. Fisher B, Dignam J, Bryant J, DeCillis A, Wickerham DL, Wolmark N, Costantino J, Redmond C, Fisher ER, Bowman DM, Deschenes L, Dimitrov NV, Margolese RG, Robidoux A, Shibata H, Terz J, Paterson AH, Feldman MI, Farrar W, Evans J, Lickley HL (1996) Five versus more than five years of tamoxifen therapy for breast cancer patients with negative lymph nodes and estrogen receptor-positive tumors. J Natl Cancer Inst 88:1529-1542

63. Fisher B, Dignam J, Bryant J, Wolmark N (2001) Five versus more than five years of tamoxifen for lymph node-negative breast cancer: updated findings from the National Surgical Adjuvant Breast and Bowel Project B-14 randomized trial. J Natl Cancer Inst 93:684-690 
64. Bhatnagar AS, Brodie AM, Long BJ, Evans DB, Miller WR (2001) Intracellular aromatase and its relevance to the pharmacological efficacy of aromatase inhibitors. J Steroid Biochem Mol Biol 76:199-202

65. Gershanovich M, Chaudri HA, Campos D, Lurie H, Bonaventura A, Jeffrey M, Buzzi F, Bodrogi I, Ludwig H, Reichardt P, O'Higgins N, Romieu G, Friederich P, Lassus M (1998) Letrozole, a new oral aromatase inhibitor: randomised trial comparing $2.5 \mathrm{mg}$ daily, $0.5 \mathrm{mg}$ daily and aminoglutethimide in postmenopausal women with advanced breast cancer. Letrozole International Trial Group (AR/BC3). Ann Oncol 9:639-645

66. NCCN Practice Guidelines in Oncology-Breast Cancer. v.2.2006. http://www.nccn.org/professionals/physician_gls/PDF/ breast.pdf Cited 17 January 2007

67. Grunfeld EA, Ramirez AJ, Maher EJ, Peach D, Young T, Albery IP, Richards MA (2001) Chemotherapy for advanced breast cancer: what influences oncologists' decision-making? $\mathrm{Br} \mathrm{J}$ Cancer 84:1172-1178

68. Jones D, Ghersi D, Wilcken N (2006) Addition of drug/s to a chemotherapy regimen for metastatic breast cancer. Cochrane Database Syst Rev 19;3:CD003368

69. Bottomley A, Biganzoli L, Cufer T, Coleman RE, Coens C, Efficace F, Calvert HA, Gamucci T, Twelves C, Fargeot P, Piccart M; European Organization for Research, Treatment of Cancer Breast Cancer Group (2004) Randomized, controlled trial investigating short-term health-related quality of life with doxorubicin and paclitaxel versus doxorubicin and cyclophosphamide as first-line chemotherapy in patients with metastatic breast cancer: European Organization for Research and Treatment of Cancer Breast Cancer Group, Investigational Drug Branch for Breast Cancer and the New Drug Development Group Study. J Clin Oncol 22:2576-2586

70. Baldini E, Prochilo T, Salvadori B, Bolognesi A, Aldrighetti D, Venturini M, Rosso R, Carnino F, Gallo L, Giannessi P, Conte PF, Orlandini C, Bruzzi P (2004) Multicenter randomized phase III trial of epirubicin plus paclitaxel vs epirubicin followed by paclitaxel in metastatic breast cancer patients: focus on cardiac safety. Br J Cancer 91:45-49

71. Wilcken N, Hornbuckle J, Ghersi D (2003) Chemotherapy alone versus endocrine therapy alone for metastatic breast cancer. Cochrane Database Syst Rev 2:CD002747

72. Dombernowsky P, Smith I, Falkson G, Leonard R, Panasci L, Bellmunt J, Bezwoda W, Gardin G, Gudgeon A, Morgan M, Fornasiero A, Hoffmann W, Michel J, Hatschek T, Tjabbes T, Chaudri HA, Hornberger U, Trunet PF (1998) Letrozole, a new oral aromatase inhibitor for advanced breast cancer: doubleblind randomized trial showing a dose effect and improved efficacy and tolerability compared with megestrol acetate. J Clin Oncol 16:453-461

73. Buzdar A, Douma J, Davidson N, Elledge R, Morgan M, Smith R, Porter L, Nabholtz J, Xiang X, Brady C (2001) Phase III, multicenter, double-blind, randomized study of letrozole, an aromatase inhibitor, for advanced breast cancer versus megestrol acetate. J Clin Oncol 19:3357-3366

74. Mouridsen H, Gershanovich M, Sun Y, Perez-Carrion R, Boni C, Monnier A, Apffelstaedt J, Smith R, Sleeboom HP, Jaenicke F, Pluzanska A, Dank M, Becquart D, Bapsy PP, Salminen E, Snyder R, Chaudri-Ross H, Lang R, Wyld P, Bhatnagar A (2003) Phase III study of letrozole versus tamoxifen as first-line therapy of advanced breast cancer in postmenopausal women: analysis of survival and update of efficacy from the International Letrozole Breast Cancer Group. J Clin Oncol 21:2101-2109

75. Irish W, Sherrill B, Cole B, Gard C, Glendenning GA, Mouridsen H (2005) Quality-adjusted survival in a crossover trial of letrozole versus tamoxifen in postmenopausal women with advanced breast cancer. Ann Oncol 16:1458-1462
76. Mouridsen H, Sun Y, Gershanovich M, Perez-Carrion R, Becquart D, Chaudri-Ross HA, Lang R (2004) Superiority of letrozole to tamoxifen in the first-line treatment of advanced breast cancer: evidence from metastatic subgroups and a test of functional ability. Oncologist 9:489-496

77. Rose C, Vtoraya O, Pluzanska A, Davidson N, Gershanovich M, Thomas R, Johnson S, Caicedo JJ, Gervasio H, Manikhas G, Ben Ayed F, Burdette-Radoux S, Chaudri-Ross HA, Lang R (2003) An open randomised trial of second-line endocrine therapy in advanced breast cancer: comparison of the aromatase inhibitors letrozole and anastrozole. Eur J Cancer 39:2318-2327

78. Thomas R, Godwardx S, Makris A, Bloomfieldk D, Moody AM, Williams M (2004) Giving patients a choice improves quality of life: a multi-centre, investigator-blind, randomised, crossover study comparing letrozole with anastrozole. Clin Oncol 16: 485-491

79. Brufsky A, Lembersky B, Schiffman K, Lieberman G, Paton VE (2005) Hormone receptor status does not affect the clinical benefit of trastuzumab therapy for patients with metastatic breast cancer. Clin Breast Cancer 6:247-252

80. De Laurentiis M, Arpino G, Massarelli E, Ruggiero A, Carlomagno C, Ciardiello F, Tortora G, D'Agostino D, Caputo F, Cancello G, Montagna E, Malorni L, Zinno L, Lauria R, Bianco AR, De Placido $S$ (2005) A meta-analysis on the interaction between HER-2 expression and response to endocrine treatment in advanced breast cancer. Clin Cancer Res 11:4741-4748

81. Witters L, Engle L, Lipton A (2002) Restoration of estrogen responsiveness by blocking the HER-2/neu pathway. Oncol Rep 9:1163-1166

82. Marcom PK, Isaacs C, Harris L, Wong ZW, Kommarreddy A, Novielli N, Mann G, Tao Y, Ellis MJ (2007) The combination of letrozole and trastuzumab as first or second-line biological therapy produces durable responses in a subset of HER2 positive and ER positive advanced breast cancers. Breast Cancer Res Treat 102:43-49

83. Kaufman B (2006) Trastuzumab plus anastrozole prolongs progression-free survival in postmenopausal women with HER2-positive, hormone-dependent metastatic breast cancer (MBC). Presented at the 31st European Society for Medical Oncology Congress, Istanbul, Turkey, 27 September-3 October 2006. Abstract LBA2

84. Study comparing GW572016 and letrozole versus letrozole in subjects with advanced or metastatic breast cancer. http://www.clinicaltrials.gov/ct/show/NCT00073528. Cited 17 January 2007

85. Thewes B, Meiser B, Duric VM, Stockler MR, Taylor A, StuartHarris R, Links M, Wilcken N, McLachlan SA, Phillips KA, Beith J, Boyle F, Friedlander ML (2005) What survival benefits do premenopausal patients with early breast cancer need to make endocrine therapy worthwhile? Lancet Oncol 6:581-588

86. Duric VM, Stockler MR, Heritier S, Boyle F, Beith J, Sullivan A, Wilcken N, Coates AS, Simes RJ (2005) Patients' preferences for adjuvant chemotherapy in early breast cancer: what makes $\mathrm{AC}$ and $\mathrm{CMF}$ worthwhile now? Ann Oncol 16: 1786-1794

87. Jansen SJ, Otten W, Stiggelbout AM (2004) Review of determinants of patients' preferences for adjuvant therapy in cancer. J Clin Oncol 22:3181-3190

88. Dixon JM, Renshaw L, Young O, Murray J, Macaskill EJ, McHugh M, Dixon OM, Folkerd E, McCaig F, Cameron D, Dowsett M, Langridge C, A'Hern R, Fallowfield LJ (2006) Anastrozole and letrozole an investigation and comparison of quality of life, tolerability and morbidity. Breast Cancer Res Treat 100(suppl 1):S24. Abstract 105 
89. Kaufmann M, Rody A (2005) Long-term risk of breast cancer recurrence: the need for extended adjuvant therapy. J Cancer Res Clin Oncol 131:487-494

90. Goss PE, Ingle JN, Martino S, Robert NJ, Muss HB, Piccart MJ, Castiglione M, Tu D, Shepherd LE, Pritchard KI, Livingston RB, Davidson NE, Norton L, Perez EA, Abrams JS, Therasse P, Palmer MJ, Pater JL (2003) A randomized trial of letrozole in postmenopausal women after five years of tamoxifen therapy for early-stage breast cancer. N Engl J Med 349:1793-1802

91. Eiermann W, Paepke S, Appfelstaedt J, Llombart-Cussac A, Eremin J, Vinholes J, Mauriac L, Ellis M, Lassus M, ChaudriRoss HA, Dugan M, Borgs M; Letrozole Neo-Adjuvant Breast Cancer Study Group (2001) Preoperative treatment of postmenopausal breast cancer patients with letrozole: A randomized double-blind multicenter study. Ann Oncol 12:1527-1532

92. Abrial C, Mouret-Reynier MA, Cure H, Feillel V, Leheurteur M, Lemery S, Le Bouedec G, Durando X, Dauplat J, Chollet P (2005) Neoadjuvant endocrine therapy in breast cancer. Breast 15:9-19

93. Dixon JM, Love CD, Bellamy CO, Cameron DA, Leonard RC, Smith H, Miller WR (2001) Letrozole as primary medical therapy for locally advanced and large operable breast cancer. Breast Cancer Res Treat 66:191-199

94. Renshaw L, Murray J, Young O, Cameron D, Miller WR, Dixon JM (2004) Is there an optimal duration of neoadjuvant letrozole therapy? Presented at the 27th Annual San Antonio Breast Cancer Symposium, 8-11 December 2004. Abstract 405

95. Ellis MJ, Coop A, Singh B, Tao Y, Llombart-Cussac A, Janicke F, Mauriac L, Quebe-Fehling E, Chaudri-Ross HA, Evans DB, Miller WR (2003) Letrozole inhibits tumor proliferation more effectively than tamoxifen independent of HER $1 / 2$ expression status. Cancer Res 63:6523-6531

96. Ellis MJ, Tao Y, Young O, White S, Proia AD, Murray J, Renshaw L, Faratian D, Thomas J, Dowsett M, Krause A, Evans DB, Miller WR, Dixon JM (2006) Estrogen-independent proliferation is present in estrogen-receptor HER2-positive primary breast cancer after neoadjuvant letrozole. J Clin Oncol 24: 3019-3025

97. Murray J, Young O, Renshaw L, White S, Prescot RJ, Krause A, Evans DB, Salem R, Cameron D, Dowsett M, Miller WR, Dixon JM (2004) Letrozole and anastrozole: a pre-operative study of their effects on ER positive breast cancers in postmenopausal women. Presented at the 27th Annual San Antonio Breast Cancer Symposium, 8-11 December 2004. Abstract 406

98. Zhu L, Chow LW, Loo WT, Guan XY, Toi M (2004) Her2/neu expression predicts the response to antiaromatase neoadjuvant therapy in primary breast cancer: subgroup analysis from celecoxib antiaromatase neoadjuvant trial. Clin Cancer Res 15;10: 4639-4644

99. Baum M, Budzar AU, Cuzick J, Forbes J, Houghton JH, Klijn JG, Sahmoud T; ATAC Trialists' Group (2002) Anastrozole alone or in combination with tamoxifen versus tamoxifen alone for adjuvant treatment of postmenopausal women with early breast cancer: first results of the ATAC randomised trial. Lancet 359:2131-2139. Erratum in: Lancet 2002;360:1520

100. Winer EP, Hudis C, Burstein HJ, Wolff AC, Pritchard KI, Ingle JN, Chlebowski RT, Gelber R, Edge SB, Gralow J, Cobleigh MA, Mamounas EP, Goldstein LJ, Whelan TJ, Powles TJ, Bryant J, Perkins C, Perotti J, Braun S, Langer AS, Browman GP, Somerfield MR (2005) American Society of Clinical Oncology technology assessment on the use of aromatase inhibitors as adjuvant therapy for postmenopausal women with hormone receptor-positive breast cancer: status report 2004. J Clin Oncol 23:619-629

101. Goss PE, Ingle JN, Martino S, Robert NJ, Muss HB, Piccart MJ, Castiglione M, Tu D, Shepherd LE, Pritchard KI, Livingston
RB, Davidson NE, Norton L, Perez EA, Abrams JS, Cameron DA, Palmer MJ, Pater JL (2005) Randomized trial of letrozole following tamoxifen as extended adjuvant therapy in receptorpositive breast cancer: updated findings from NCIC CTG MA.17. J Natl Cancer Inst 97:1262-1271

102. Goss PE, Ingle JN, Palmer MJ, Shepherd LE, Tu D (2005) Updated analysis of NCIC CTG MA.17 (letrozole vs. placebo to letrozole vs. placebo) post unblinding. Breast Cancer Res Treat 94(suppl 1):S10. Abstract 16

103. Bushnell CD, Goldstein LB (2004) Risk of ischemic stroke with tamoxifen treatment for breast cancer: a meta-analysis. Neurology 63:1230-1233

104. Goldhirsch A, Glick JH, Gelber RD, Coates AS, Thurlimann B, Senn HJ; Panel members (2005) Meeting highlights: international expert consensus on the primary therapy of early breast cancer 2005. Ann Oncol 16:1569-1583

105. AGO Breast Commission (2007) Diagnostic and treatment of patients with primary and metastatic breast cancer. http://www.ago-online.de. Latest update July 17, 2007

106. Viale G, Regan M, Dell'Orto P, Del Curto B, Braye S, Orosz Z, Brown R, Olszewski WP, Knox F, Oehlschlegel C, Thürlimann $\mathrm{B}$; the BIG 1-98 Collaborative International Breast Cancer Study Group (2005) Central review of ER, PgR and HER-2 in BIG 1-98 evaluating letrozole vs. tamoxifen as adjuvant endocrine therapy for postmenopausal women with receptor-positive breast cancer. Breast Cancer Res Treat 94(suppl 1):S13. Abstract 44

107. Wardley AM (2006) Emerging data on optimal adjuvant endocrine therapy: Breast International Group trial 1-98/MA.17. Clin Breast Cancer 6(suppl 2):S45-S50

108. Jakesz R, Jonat W, Gnant M, Mittlboeck M, Greil R, Tausch C, Hilfrich J, Kwasny W, Menzel C, Samonigg H, Seifert M, Gademann G, Kaufmann M, Wolfgang J; ABCSG, the GABG (2005) Switching of postmenopausal women with endocrineresponsive early breast cancer to anastrozole after 2 years' adjuvant tamoxifen: combined results of ABCSG trial 8 and ARNO 95 trial. Lancet 366:455-462

109. Boccardo F, Rubagotti A, Puntoni M, Guglielmini P, Amoroso D, Fini A, Paladini G, Mesiti M, Romeo D, Rinaldini M, Scali S, Porpiglia M, Benedetto C, Restuccia N, Buzzi F, Franchi R, Massidda B, Distante V, Amadori D, Sismondi P (2005) Switching to anastrozole versus continued tamoxifen treatment of early breast cancer: preliminary results of the Italian Tamoxifen Anastrozole Trial. J Clin Oncol 23:5138-5147

110. Jonat W, Gnant M, Boccardo F, Kaufmann M, Rubagotti A, Jakesz R (2005) Switching from adjuvant tamoxifen to anastrozole in postmenopausal women with hormone-responsive early breast cancer: a meta-analysis of the ARNO 95 trial, ABCSG Trial 8, and the ITA trial. Breast Cancer Res Treat 94(suppl 1):S11. Abstract 18

111. Kaufmann M, Jonat W, Hilfrich J, Eidtmann H, Gademann G, Zuna I, Von Minckwitz G, on behalf of the German Adjuvant Breast Cancer Group (2006) Survival benefit of switching to anastrozole after 2 years' treatment with tamoxifen versus continued tamoxifen therapy: the ARNO 95 study. J Clin Oncol 24(18S): 14 s. Abstract 547

112. Johnson Vickberg SM (2001) Fears about breast cancer recurrence. Cancer Pract 9:237-243

113. Chia SK, Speers CH, Bryce CJ, Hayes MM, Olivotto IA (2004) Ten-year outcomes in a population-based cohort of nodenegative, lymphatic, and vascular invasion-negative early breast cancers without adjuvant systemic therapies. J Clin Oncol 22:1630-1637

114. Whelan TJ, Pritchard KI (2006) Managing patients on endocrine therapy: focus on quality-of-life issues. Clin Cancer Res 12(3 Pt 2):1056s-1060s 
115. Whelan TJ, Goss PE, Ingle JN, Pater JL, Tu D, Pritchard K, Liu S, Shepherd LE, Palmer M, Robert NJ, Martino S, Muss HB (2005) Assessment of quality of life in MA.17: a randomized, placebo-controlled trial of letrozole after 5 years of tamoxifen in postmenopausal women. J Clin Oncol 23:6931-6940

116. Glaus A, Boehme Ch, Thurlimann B, Ruhstaller T, Hsu Schmitz SF, Morant R, Senn HJ, von Moos R (2006) Fatigue and menopausal symptoms in women with breast cancer undergoing hormonal cancer treatment. Ann Oncol 17:801-806

117. Lash TL, Fox MP, Westrup JL, Fink AK, Silliman RA (2006) Adherence to tamoxifen over the five-year course. Breast Cancer Res Treat 99:215-220

118. Thomas RJ, Marshall C, Williams M, Walker LG (2006) Switching to adjuvant letrozole improves hot flushes, mood, and quality of life in the tamoxifen intolerant subgroup. Ann Oncol 17(suppl 9):ix100. Abstract 264P

119. Perez EA, Josse RG, Pritchard KI, Ingle JN, Martino S, Findlay BP, Shenkier TN, Tozer RG, Palmer MJ, Shepherd LE, Liu S, Tu D, Goss PE (2006) Effect of letrozole versus placebo on bone mineral density in women with primary breast cancer completing 5 or more years of adjuvant tamoxifen: a companion study to NCIC CTG MA.17. J Clin Oncol 24:3629-3635

120. Brufsky A, Harker WG, Beck JT, Carroll R, Tan-Chiu E, Seidler C, Hohneker J, Lacerna L, Petrone S, Perez EA (2007) Zoledronic acid inhibits adjuvant letrozole-induced bone loss in postmenopausal women with early breast cancer. J Clin Oncol 25:829-836

121. Bundred N, Campbell I, Coleman R, DeBoer R, Eidtmann H, Frassolati A, Llombart A, Monnier A, Neven P, Dias R (2006) Zoledronic acid in the prevention of cancer treatment-induced bone loss in postmenopausal women receiving letrozole as adjuvant therapy for early breast cancer (ZOFAST study). Eur J Cancer Suppl 4(2):48. Abstract 12

122. Coleman RE, on behalf of the ATAC Trialists' Group (2006) Effect of anastrozole on bone mineral density: 5-year results from the Arimidex, Tamoxifen, Alone or in Combination (ATAC) trial. J Clin Oncol 24(18S):5s. Abstract 511

123. Buzdar A et al behalf of the ATAC Trialists' Group (2006) Clinical features of joint symptoms observed in the Arimidex, Tamoxifen, Alone or in Combination (ATAC) trial. J Clin Oncol 24(18S): 15s. Abstract 551

124. Ganz PA, Desmond KA, Belin TR, Meyerowitz BE, Rowland JH (1999) Predictors of sexual health in women after a breast cancer diagnosis. J Clin Oncol 17:2371-2380

125. Gupta P, Sturdee DW, Palin SL, Majumder K, Fear R, Marshall T, Paterson I (2006) Menopausal symptoms in women treated for breast cancer: the prevalence and severity of symptoms and their perceived effects on quality of life. Climacteric 9:49-58

126. Burwell SR, Case LD, Kaelin C, Avis NE (2006) Sexual problems in younger women after breast cancer surgery. J Clin Oncol $24: 2815-2821$
127. Ganz PA, Greendale GA, Petersen L, Zibecchi L, Kahn B, Belin TR (2000) Managing menopausal symptoms in breast cancer survivors: results of a randomized controlled trial. J Natl Cancer Inst 92:1054-1064

128. Kendall A, Dowsett M, Folkerd E, Smith I (2006) Caution: vaginal estradiol appears to be contraindicated in postmenopausal women on adjuvant aromatase inhibitors. Ann Oncol 17:584-587

129. Davis SR, Goldstat R, Papalia MA, Shah S, Kulkarni J, Donath S, Bell RJ (2006) Effects of aromatase inhibition on sexual function and well-being in postmenopausal women treated with testosterone: a randomized, placebo-controlled trial. Menopause 13:37-45

130. Francini G, Petrioli R, Montagnani A, Cadirni A, Campagna S, Francini E, Gonnelli S (2006) Exemestane after tamoxifen as adjuvant hormonal therapy in postmenopausal women with breast cancer: effects on body composition and lipids. $\mathrm{Br} \mathrm{J}$ Cancer 95:153-158

131. The Arimidex, Tamoxifen, Alone or in Combination Trialists' Group, Buzdar A, Howell A, Cuzick J, Wale C, Distler W, Hoctin-Boes G, Houghton J, Locker GY, Nabholtz JM (2006) Comprehensive side-effect profile of anastrozole and tamoxifen as adjuvant treatment for early-stage breast cancer: long-term safety analysis of the ATAC trial. Lancet Oncol 7:633-643

132. McCloskey E, Eastell R, Lakner G, Miyamoto A, Clack G (2005) Initial results from the LEAP study: the first direct comparison of safety parameters between aromatase inhibitors in healthy postmenopausal women. Breast Cancer Res Treat 94(suppl 1):S1001. Abstract 2052

133. Wasan KM, Goss PE, Pritchard PH, Shepherd L, Palmer MJ, Liu S, Tu D, Ingle JN, Heath M, Deangelis D, Perez EA (2005) The influence of letrozole on serum lipid concentrations in postmenopausal women with primary breast cancer who have completed 5 years of adjuvant tamoxifen (NCIC CTG MA.17L). Ann Oncol 16:707-715

134. Paley M, Love N, Carlson R, Tripathy D, Kaderman R, Paley D, Dvorkin J, Ziel K (2005) Preferences for oral and parenteral antitumor therapy: a survey of 260 patients with metastatic breast cancer. J Clin Oncol 23(16S):33s. Abstract 619

135. GAEA press release (2006) Large European survey reveals critical gaps in breast cancer patient education and communication. http://www.medicalnewstoday.com/medicalnews.php?newsid= 53364 Cited 17 January 2007

136. Wengstrom Y, Alberto Costa, Jan Koedam, Vasoulla Georgiou (2006) Women's experience and knowledge of adjuvant Endocrine therapy (AET) for early breast cancer (bc): a European survey. Ann Oncol 17(suppl 9):ix99. Abstract 262P

137. Femara Prescribing Information (2005) Novartis 